\title{
Bio-inspired Parametric Design for Adaptive Stadium Façades
}

Jong Jin Park and Bharat Dave (The University of Melbourne, Australia)

\begin{abstract}
The challenge of developing sustainable, adaptive architecture requires unconventional approaches to innovative knowledge about composition and dynamic interaction between building façades and environmental conditions. These approaches are often inspired by biology, its complex fine-tuned behaviour and integration of living systems. This paper proposes a system inspired from the optics of reflecting superposition compound eyes to create responsive façade structures that capture and distribute daylight within a building in response to the movement of the sun. This is investigated using the parametric reshaping of a building envelop as part of solar radiation and target ray simulations. The prototype façade system is capable of adapting to different functional needs, locations, times of the day, and other contextual conditions.
\end{abstract}

Keywords: Biomimetics, kinetic/adaptive façades, reflecting superposition compound eyes

\section{Introduction}

Within contemporary sports architecture there is a growing interest in energy-efficient building designs. According to the Commercial Buildings Energy Consumption Survey (CBECS) conducted by the U.S. Energy Information Administration (EIA), approximately $65 \%$ of total energy consumed in commercial buildings is used for space heating, cooling and lighting. Similarly, sports facilities demand tremendous energy consumption to meet requirements on indoor comfort level for players and spectators, resulting in adoption of active technologies such as artificial lighting, HVAC systems, and et cetera.

Parallel to this, development of digital design tools and corresponding techniques open new possibilities of intelligent façades that adapt to specific demands, for instance, environment conditions and user occupancy (Wigginton and Harris, 2002). The role of building envelopes developed by such technologies as part of sports facility designs, however, tends to be largely aesthetic or symbolic with less consideration for passive building performance. Bioinspired design approach, in such a case, is likely to be a promising solution not only to generate diverse alternative design proposals but also to attain both sustainability and longterm adaptability as part of environmental concerns. This research focuses on parametric design process inspired by the optics of reflecting superposition compound eyes for designing adaptive stadium façades. Their highly developed compositional and optical features have the potential to offer a unique focusing and distributing effect and daylight intensity adjustment in terms of building performance criteria. The proposed design strategy is employed in the prototype of a gymnasium utilising daylight as a key passive design element to improve adaptivity and responsiveness to the environmental context.

\section{Biological Adaptation}

Biology has been used as an inspiration for architectural designs because of the perfectly optimised living systems, which have continuously evolved over the course of generations. The adaptation of an organism to its environment can be compared to the harmonious relation of a building to its surroundings and its appropriateness for the various purposes for which it is intended (Steadman, 2008). In biology, change is the evolutionary process which leads organisms to acclimatise to their environment in various levels and scales. Today, architects utilise forms, functions, behaviours, or entire ecosystems of living organisms as a 
source of design creativity and sustainability. They generate built environment with advanced digital technologies, based on the lessons drawn from nature.

Learning from nature involves a process of knowledge translation into appropriate design languages in the architectural context. Although this process does not always result in design solutions that directly correspond to the inspiring living organism due to the different contextual conditions, it is important to thoroughly examine how living organisms deal with the similar problems and then to adjust their functional principles for application to our design problems.

\section{Daylight and Building Environment}

The importance of utilising ambient natural elements as primary energy sources for buildings has attracted increasing interests from architects ever since building sustainability became widespread in the field. Of the natural elements that flow to and from the built environment as key energy sources is sunlight, or solar energy, which is the sole source of power of the closed loop ecosystem of earth. When designing envelopes for indoor or semi-outdoor sports facilities, incoming daylight through building skins becomes a determining factor for performative conditions of the spaces underneath. Given that the interaction of sunlight and building envelope is a key contributor to the higher performance efficiency of buildings, this research proposes daylight as a key design feature for responsive façade systems.

\section{Adaptive Façade Components}

\section{Sustainability, Energy Efficiency and Sports Facilities}

Of the natural elements that flow to and from to the built environment as key energy sources is sunlight, or solar energy, which is the sole source of power of the closed loop ecosystem of earth. Provided that the hours of daylight and the diurnal variation are predictable based on the long-accumulated statistical weather data, daylight value becomes one of the most important primary concerns for sustainability of built environments in response to ambient conditions. When focusing on large roofs like those for gymnasiums, two aspects are highlighted. One is the area underneath the roofs such as pitch and tier area, which takes advantage of possible overhead natural light either coming through openings or transmitted through the roof. The other aspect is the consequent configurations of openings or components that can include inclinations and orientations to balance the incoming direct and indirect light. These two aspects are largely affected by geometry of the roof and its components as well as its material properties (Figure 1).

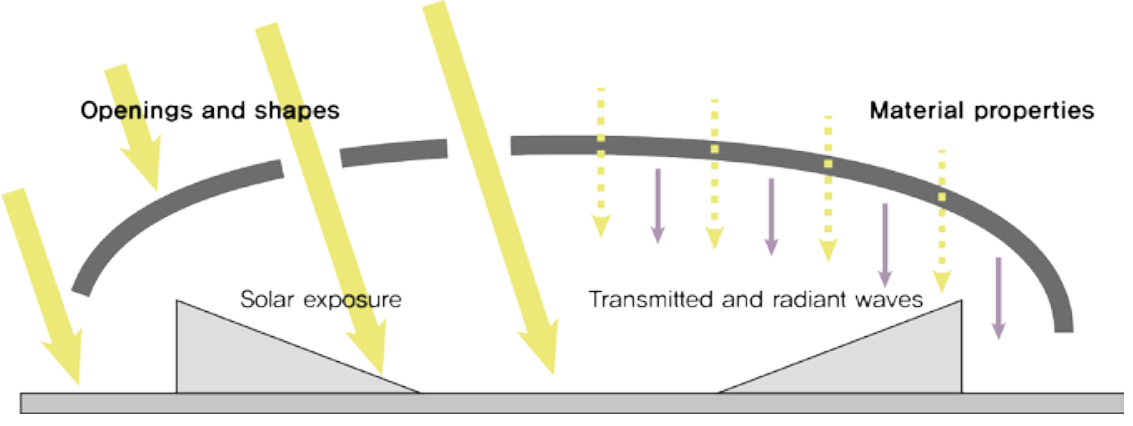

Figure 1: Effect of openings, shapes, and material properties of the building façade on the incident sunlight (Source: Park \& Dave, 2013)

The proposed façade system related to daylight concerns these two aspects to adapt the building form to help reduce the need for active systems by controlling natural light inside. Such building façade systems anticipate being capable of capturing and distributing useful 
solar radiation inside as well as rejecting unwanted radiation to reduce reliance on external energy inputs.

\section{Daylighting Requirements}

The daylight requirements vary according to different functional demands for various events taking place. The amount of total daylight reaching in the pitch area as intended is the fundamental factor that addresses performance criteria for this research, and can be quantified by solar insolation, illuminance levels and daylight factor (measured in $\mathrm{Wh} / \mathrm{m}^{2}$, Lux, and percentage, respectively). Daylight factor measures relative illumination within a space compared to that of a standardised overcast sky condition (Mardaljevic et al., 2009). A minimum illuminance level for a gymnasium, specified by the IESNA (Illuminating Engineering Society of North America) Lighting Handbook, is 300 lux for general exercising and recreation, and 1,000 lux for sports matches. During the daylight simulation, the proposed façade system will be evaluated based on these indices in terms of adaptivity and flexibility for the façade to be responsive to the daylight conditions.

\section{Reflecting Superposition Compound Eyes}

This research involves investigation of natural organisms that regulate light perception in their living environment, specifically focusing on their optics and adaptation to light. Superposition compound eyes, which can be easily found in the long-body decapod crustaceans such as shrimps, prawns, and lobsters (Land, 2000), produce single erect images on a retina by three mechanisms: refracting, reflecting, and mixed or parabolic superposition. Of the three systems, reflecting superposition compound eyes allow to form an image over a wide field of view with corner-reflector configuration. Their eyes consist of tapered tubes having square facets and reflective interior surfaces to redirect incoming light to a particular shared rhabdom as seen in Figure $2 \mathrm{C}$.

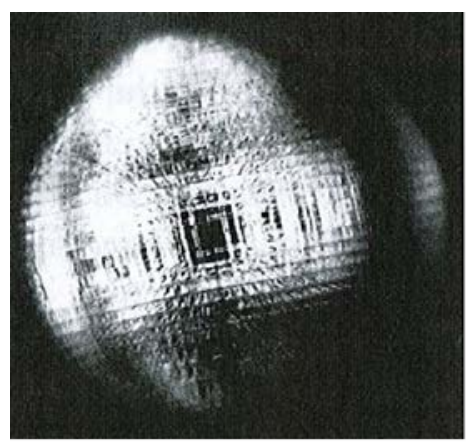

A

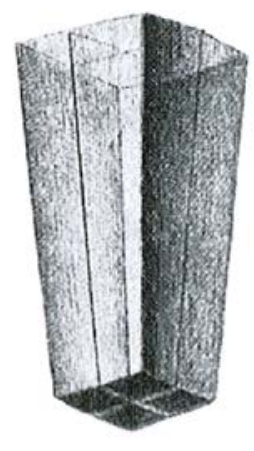

B

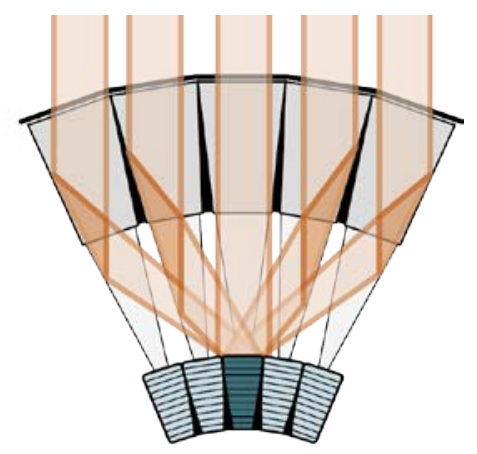

C

Figure 2: Reflecting superposition eyes: (A) eye of the decapod shrimp, (B) tapered mirror box in a shrimp drawn by Grenacher in 1979, (C) cross-sectional schematic of reflecting superposition eyes

The principle of corner reflector is to redirect the rays so that they emerge in the same plane parallel to their original path. Rays coming in a parallel direction with one of the sides of the crystalline cone are reflected once whereas all the other oblique rays must be reflected twice by two orthogonal sides of the mirror box, through a total of two right angles. Such an arrangement creates the same effect as a single mirror that always reflects the ray perpendicularly (Figure 3 ). This phenomenon of corner reflecting helps to obtain a clear image over a wide angular field. This mirrorbox design only works with right-angle corners, which accounts for the square facets. 

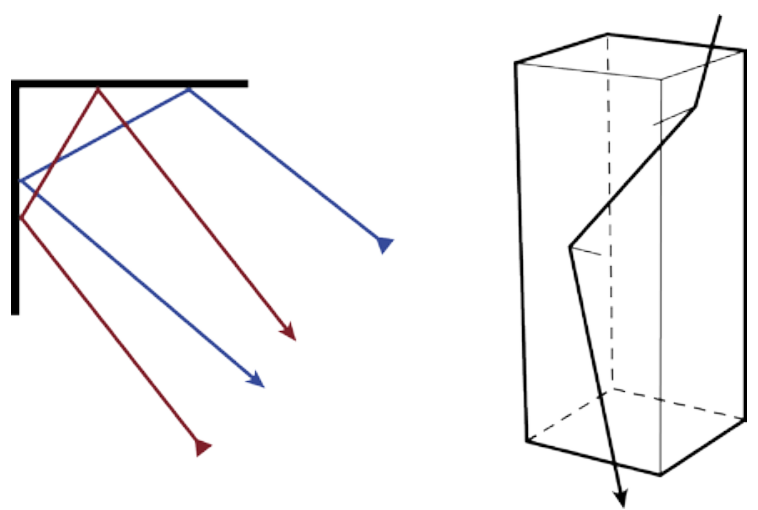

Figure 3: The principle of corner reflector. The two reflections re-direct an oblique ray in the orthogonal mirror box. (Source: Vogt, 1977)

Based on the structural compositions of the superposition compound eye having multiple facets and its optical principle that the light rays fall from multiple lenses onto a shared retina, this research takes the superposition compound eyes as a biomimetic inspiration to achieve responsive façade systems.

\section{Prototype Implementation}

\section{Design Methodology}

The optical structure of reflecting superposition eyes is converted into responsive façade components with square tube structures as a roof structure. Each tube component consistently adjusts itself according to seasonal solar radiation and sun path, and redirects sunlight to meet the aforementioned daylight and functional requirements. In order to define the structural configuration of such a façade system, a parametric approach has been developed with two main phases. The first phase concerns the parametrisation and translation of the optical structure of the eye into architectural geometries. Specifically, this parametrisation is based on the surface subdivision by angular separation over the roof surface and the tapered extrusion of each surface module to generate individual tube components. The second phase concerns the kinetic mechanism of each component module responding to the sun movement to redirect sunlight based on either environmental conditions or functional demands.
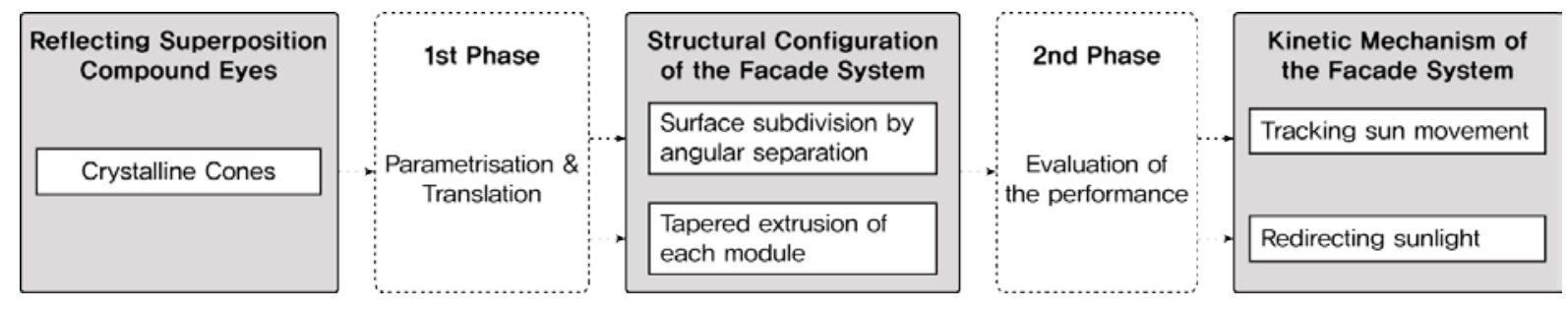

Figure 4: Diagram of the two phases of parametric process to define the structural and functional configurations of the proposed façade system

\section{Primary Parametrisation}

In order to define architectural parameters, the configuration of the "ideal" superposition eye (Land et al., 1979) was used as a starting point. In the ideal superposition eye, the point of intersection of the crystalline cone axes is the centre of curvature of the eyes, and the cones and distal rhabdom tips lie on hemispheres

Park, J. J \& Dave, B. 2014, 'Bio-inspired Parametric Design of Adaptive Stadium Facades’, Australasian Journal of Construction Economics and Building Conference Series, 2(2), 27-35. 
concentric with the outer surface of the eye. Based on the research of optical and anatomical changes of the superposition eye model, the following parameters from optical structures are converted into architectural form: $R$, radius of curvature of outer eye; $r$, radius of curvature of rhabdom; $L$, cone length; $D$, diameter of corneal facets; $\Delta \varphi$, the angle between neighboring ommatidia. Then, the configuration model goes through an optimisation process with other optical and anatomical features of reflecting superposition eyes (Table 1 ). Figure 5 shows a schematic diagram of geometrical conversion from optical structure of the eye to their corresponding architectural parameters.

Using incidence and reflection angles of sunlight onto the prototype façade surfaces, the process calculates the point at which the ray intersects with the surface of the pitch area. Those intersection points can be either distributed evenly over the pitch surface, or focused on specific zones according to various functional demands.

Table 1: Features of reflecting superposition eyes selected for architectural parameters

\begin{tabular}{|c|c|c|}
\hline Features & Descriptions & References \\
\hline $\begin{array}{l}\text { Square facets and } \\
\text { corner reflecting } \\
\text { effect }\end{array}$ & $\begin{array}{l}\text { The crystalline cones consist of square facets and rely on } \\
\text { reflective sides to reflect incident light to a common focus. }\end{array}$ & Land, 2000 \\
\hline \multirow[t]{2}{*}{$\begin{array}{l}\text { Reducing spherical } \\
\text { aberration }\end{array}$} & $\begin{array}{l}\text { Rhabdom layer has a radius of curvature approximately } \\
\text { equal to half that of the eye surface. }\end{array}$ & \multirow[t]{2}{*}{ Land et al., 1979} \\
\hline & $\begin{array}{l}\text { The axes of the crystalline cones are directed to a point } \\
\text { lying twice as deep as the receptor layer. }\end{array}$ & \\
\hline Image surface & $\begin{array}{l}\text { The receptor layer is either flat or only slightly curved in } \\
\text { order for other points in the image region to receive a } \\
\text { good image as well. }\end{array}$ & Land et al., 1979 \\
\hline $\begin{array}{l}\text { Screening pigment } \\
\text { migration }\end{array}$ & $\begin{array}{l}\text { Screening pigment migrates into the clear zone to } \\
\text { regulate light flux in the clear zone by cutting off light rays. }\end{array}$ & $\begin{array}{l}\text { Exner, 1891; Land } \\
\text { \& Nilsson, } 2012\end{array}$ \\
\hline Crystalline cones & Crystalline cones are tapered by 8 degrees. & Land, 1976 \\
\hline
\end{tabular}

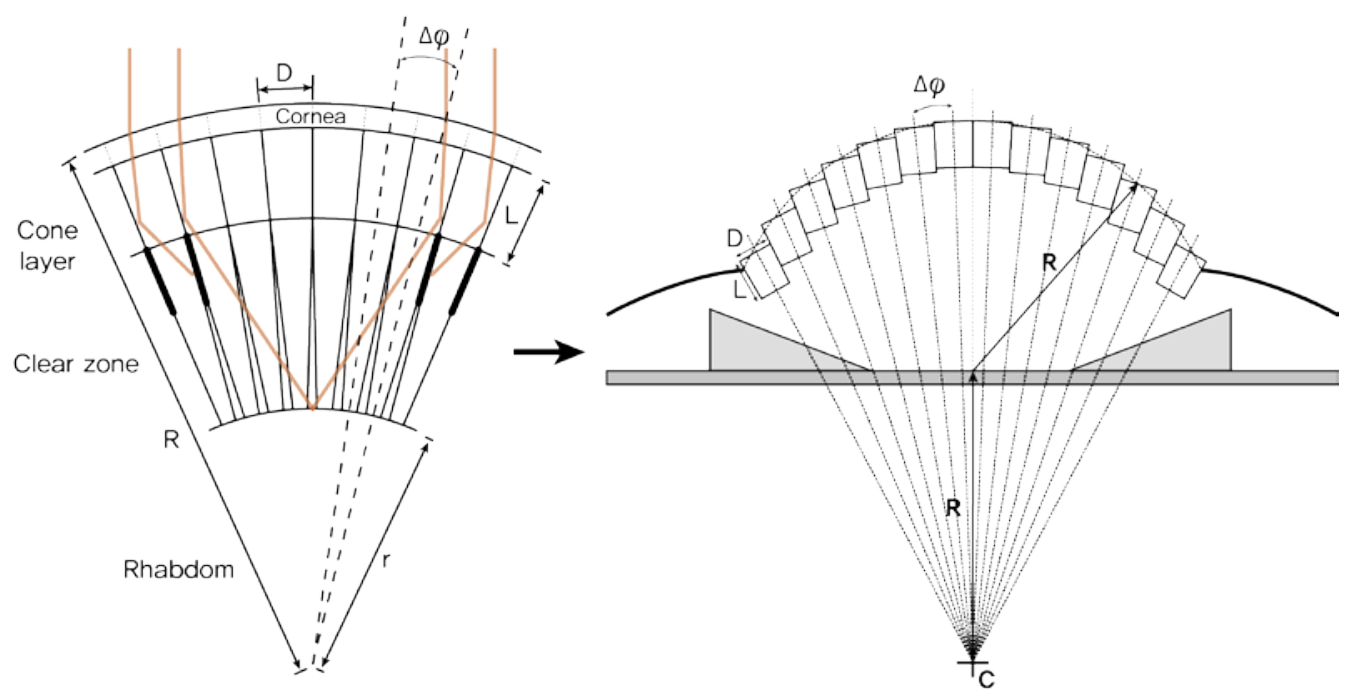

Figure 5: Geometric parameters of the eye and its corresponding conversion into architectural form 


\section{Responsive Component Design}

The particular building type used as an illustrative case for this research is a gymnasium for badminton located in Incheon, Korea at $37.5^{\circ}$ northern latitude and $126.6^{\circ}$ east of Greenwich. The proposed biomimetic strategy is implemented as a prototype to generate responsive building façades of this gymnasium by using Rhino3D and its graphical algorithm editor, Grasshopper. On the basis of the cuboid structure generated from the subdivided roof surface, adaptive façade components are defined as a tapered rectangular prism. Each façade component is capable of adjusting itself according to the sun path by shifting the bottom of the components to meet either environmental or functional needs.
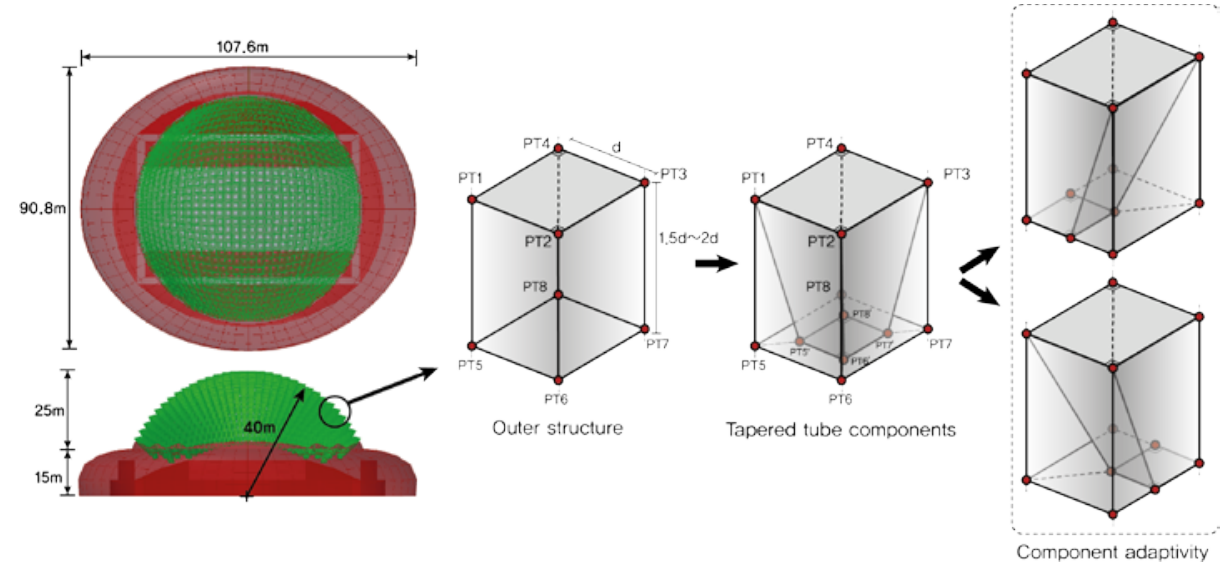

Figure 6: Configuration of adaptive façade components

Kinetic mechanism of shifting the lower end of façade components has advantages of enhancing adaptivity of the façade corresponding to two different objectives: maintaining illuminance condition of the pitch area responding to different sun elevations, and changing illuminance condition for different functional purposes (Figure 7).
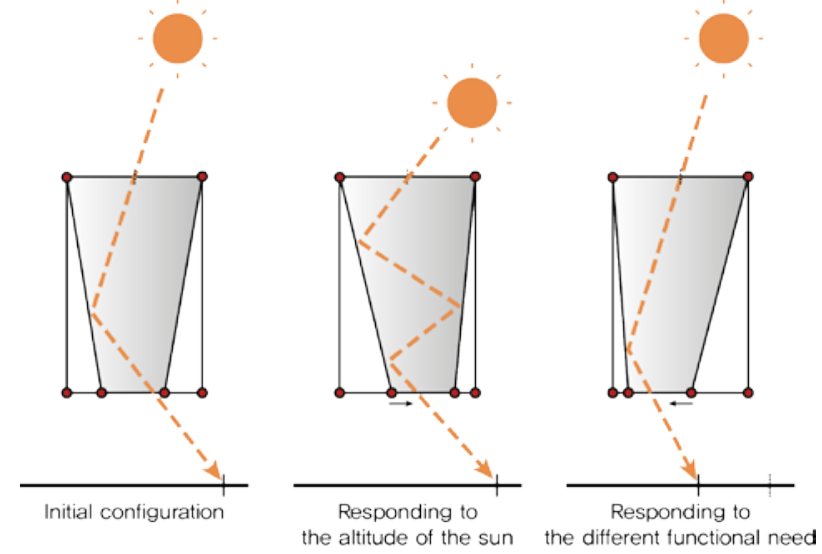

Figure 7: Shifting façade components for different illuminance purposes

\section{Performance Simulation of the Prototype}

The prototype is tested against an actual sun component of the weather data derived from the Typical Meteorological Year 2 (TMY2) weather format. Environmental data input and analysis was made seamlessly in real time through the use of Geco, a set

Park, J. J \& Dave, B. 2014, 'Bio-inspired Parametric Design of Adaptive Stadium Facades’, Australasian Journal of Construction Economics and Building Conference Series, 2(2), 27-35. 
of components for Grasshopper which link geometric data from Rhino/Grasshopper to the building performance simulation application, Autodesk Ecotect.

\section{Daylight Reflection Simulation}

Figure 8 shows the result of sunlight ray simulation with "ideal" incident rays falling onto the façade surface perpendicularly from the sky. Sunlight rays are reflected on the sides of the façade components and focused mostly on the centre of the pitch area as in the case of an ideal reflecting superposition eye.

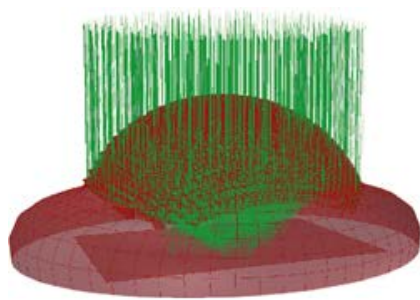

Perspective view

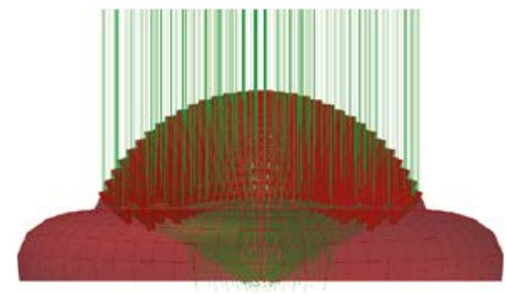

Side view

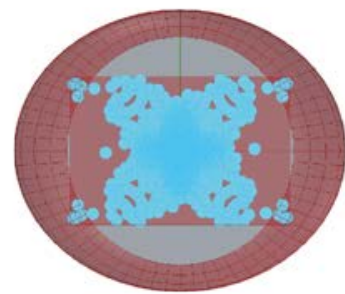

Distribution diagram of reflected rays

Figure 8: Diagram of 'ideal' incident sunlight rays distributed on the pitch area by the reflective façade component modules

Sunlight in reality, however, does not always fall onto the surface perpendicularly. Due to the constant changes of azimuths and altitudes of the sun, the pitch area is not illuminated evenly as intended. Without adaptive mechanism, one side of the pitch gets more sunlight rays reflected from the reflective façade components than other sides (Figure 9). On the other hand, the adaptive mechanism of the proposed façade system offers flexibility for façade components to change their configurations, which in turn can reflect sunlight rays at different angles into specific zones of the pitch area (Figure 10).
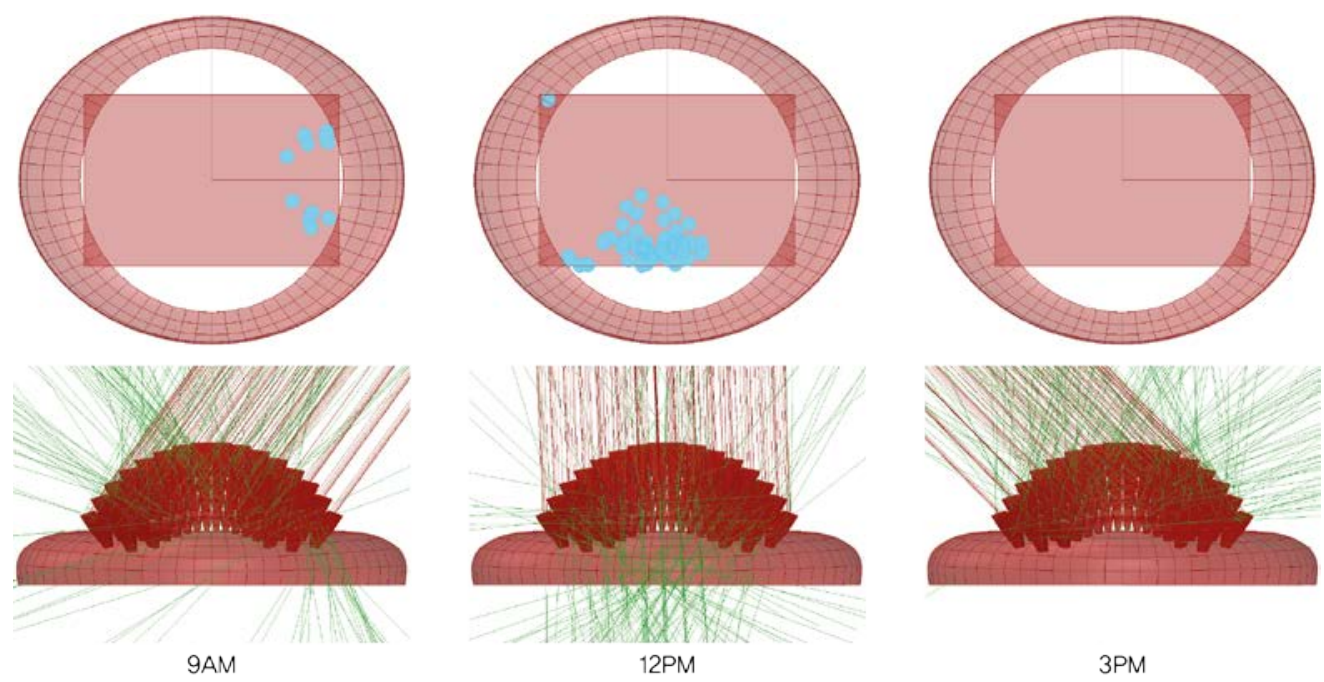

Figure 9: Result of the reflection test of sunlight rays at different time frames (blue circles represent the illuminated spots by direct sunlight rays) 

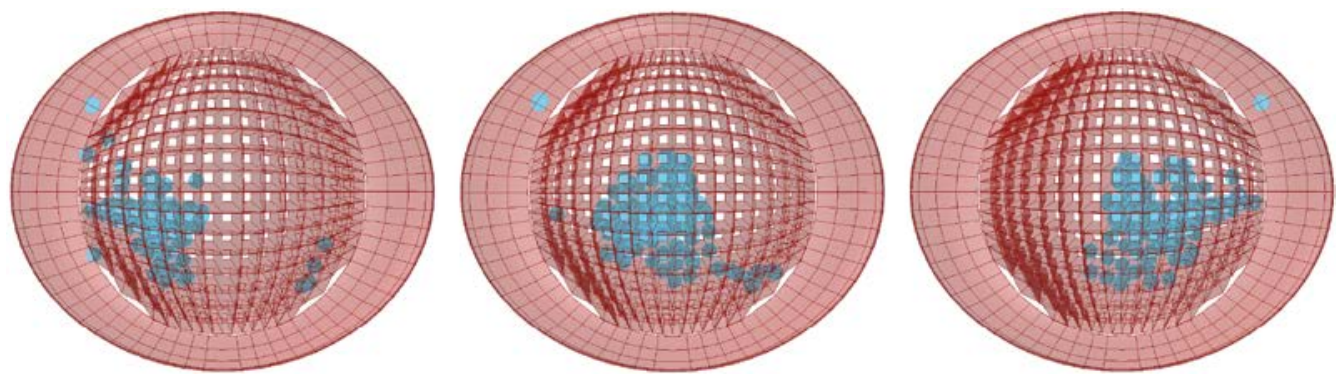

Figure 10: Different illuminance conditions realised by changing configurations of responsive modules simulated at $12 \mathrm{pm}$ on the summer solstice

\section{Solar Insolation and Daylighting Analysis}

Similar to reflection simulations, the results of solar insolation analysis show that the adaptive mechanism of the façade components affect internal illumination conditions with different location of the nodes with the highest and the lowest values of radiation analysis. These variations, with controlled manipulations of individual façade module, help control the illuminance conditions for various events other than sports matches (Figure 11). Table 2 demonstrates quantitative results on how shifting façade components affect one-hour cumulative solar radiation values from 12PM of each variation and their highest and lowest values on different spots of the pitch. In addition, the result of the daylighting analysis illustrates the overall satisfied illuminance levels inside the gymnasium, mostly much higher than 1,000 lux which is the minimum illuminance level for sports matches, due to the abundant influx of directly incoming sunlight rays that pass through the transparent surfaces on top of the façade components.

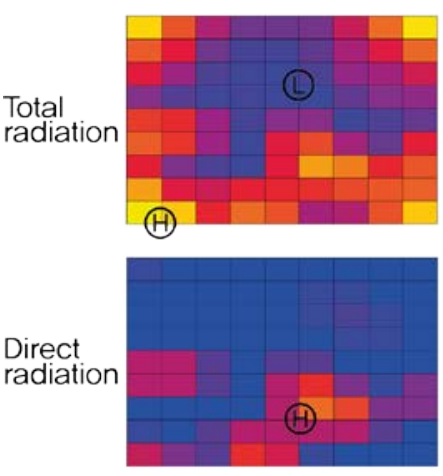

A
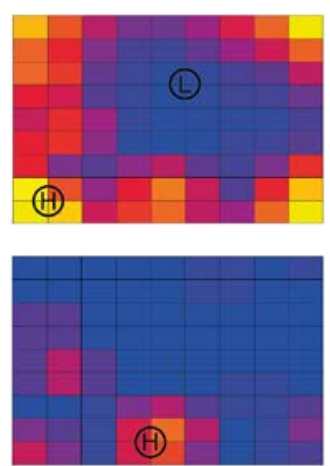

B
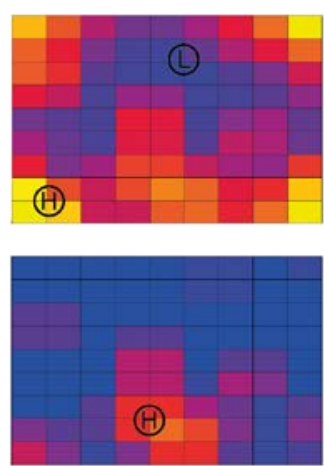

C
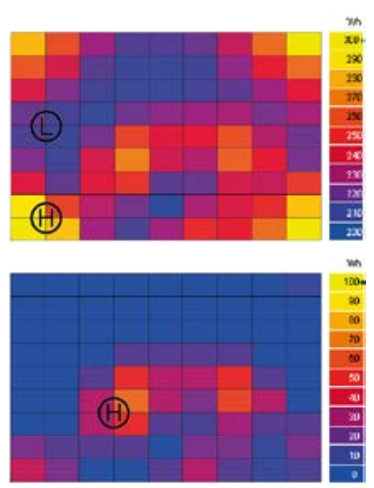

$\mathrm{D}$

Figure 11: Results of solar insolation simulations of four cases. (A) without adaptive mechanism, (B-D) three different variations with adaptive mechanism

Table 2: The highest and the lowest solar radiation values of the initial configuration $(A)$ and three other variations (B-D)

\begin{tabular}{l|l|r|r|r|r}
\hline \multicolumn{2}{l|}{} & \multicolumn{1}{c|}{ A } & \multicolumn{1}{c|}{ B } & \multicolumn{1}{c|}{ C } & \multicolumn{1}{c}{ D } \\
\hline \multirow{2}{*}{ Total radiation (Wh) } & Highest value & 380.82 & 399.19 & 399.19 & 399.19 \\
\cline { 2 - 6 } & Lowest value & 202.17 & 198.03 & 204.00 & 202.69 \\
\hline Direct radiation (Wh) & Highest value & 63.90 & 63.90 & 63.90 & 63.90 \\
\hline
\end{tabular}

Park, J. J \& Dave, B. 2014, 'Bio-inspired Parametric Design of Adaptive Stadium Facades', Australasian Journal of Construction Economics and Building Conference Series, 2(2), 27-35. 


\section{Conclusion}

This paper presented an illustrative prototype of building façade design system based on adaptive components inspired by superposition compound eyes of animals. The individual adaptive component of the proposed façade is differentiated into various configurations depending on its respective location on the façade with respect to sun positions. The adaptive system identifies different target zones on the pitch area that need to be illuminated according to the functional demands. Also, it is able to adjust the configuration of responsive components to block out the sunlight to achieve dimmed illuminance conditions for other purposes.

The proposed architectural design approach has some inherent advantages and disadvantages. Advantages of the proposed design system include: (1) enhanced day lighting conditions, (2) optimised indoor illumination quality, (3) unique architectural style of façade, (4) reduction in energy consumption, (5) controlled and optimised solar gains and insolation in interior spaces. Its disadvantages may be: (1) complex electromechanical system, (2) additional systems required to automatically sense the environmental changes, and (3) possible high maintenance cost.

The implemented computational research prototype demonstrates that adaptive architectural elements can be designed with an ecological perspective as well as functional performance, wherein they respond in topology to the constantly changing environmental parameters. The increasing power of parametric design tools enables such essential design explorations, and opens broader opportunities for building systems to adapt on their own to environmental changes and to become more passively energy-efficient by using ambient natural resources. Finally much more investigation into mechanical applications is required: since the prototype development was only based on building performance criteria with virtual surface modeling, more significant researches with how prototypes could mechanically be realised are required in order to develop more practical and advanced responsive components for dynamic responsiveness.

\section{References}

Exner, S., 1891, Die Physiologie Der Facettierten Augen Von Krebsen Und Insecten, Franz Deuticke, Leipzig \& Vienna.

Land, M.F., 1976, 'Superposition images are formed by reflection in the eyes of some oceanic decapod crustacea', Nature, 263 (5580), 764-5.

Land, M.F., 2000, 'Eyes with mirror optics', Journal of Optics A: Pure and Applied Optics, 2 (6), 44-50. Land et al., 1979, 'The Optical Geometry of Euphausiid Eyes', Journal of Comparative Physiology A, 130 (1), 49-62.

Land, M.F. \& Nilsson, D., 2012, Animal Eyes, Oxford University Press, Oxford.

Mardaljevic, J., Heschong, L. \& Lee Mac, E., 2009, 'Daylight metrics and energy savings', Lighting Research and Technology, 41 (3), 261-283.

Park, J.J. \& Dave, B., 2013, 'Bio-inspired responsive façades', Proceedings CESBP 2013, A. Mahdavi \& B. Martens (eds), The $2^{\text {nd }}$ Central European Symposium on Building Physics, 9-11 Sept., Vienna Steadman, P., 2008, The Evolution of Designs: Biological Analogy in Architecture and the Applied Arts, Routledge, New York.

Vogt, K., 1977, 'Ray Path and Reflection Mechanisms in Crayfish Eyes', Z. Naturforsch, 32, 466-468 Wigginton, M. \& Harris, J., 2002, Intelligent Skins, Architectural Press, Oxford. 